- Transplanted hearts are supersensitive to the effects of circulating catecholamines. This paper examines the haemodynamic effects of dental local anaesthetics containing 1:80,000 epinephrine (adrenaline) in patients with cardiac transplants.

- The epinephrine in dental local anaesthetics did not affect blood pressure in cardiac transplant recipients.

- Epinephrine contained in dental local anaesthetics significantly increased heart rate in cardiac transplant recipients before periodontal surgery.

- Surgery did not mask the haemodynamic changes produced by the local anaesthetic in cardiac transplant recipients.

- Epinephrine-free solutions may be preferred for dental local anaesthesia in cardiac transplant recipients.

\title{
Effects of dental local anaesthetics in cardiac transplant recipients
}

\author{
J. G. Meechan, ${ }^{1}$ G. Parry, ${ }^{2}$ D.T. Rattray ${ }^{3}$ and J. M. Thomason ${ }^{4}$
}

\begin{abstract}
Objective To investigate the cardiovascular responses of cardiac transplant recipients to dental local anaesthetic solutions with and without epinephrine (adrenaline).
\end{abstract}

Materials and methods A clinical study employing 30 patients (20 cardiac transplant recipients and ten healthy) awaiting gingival or minor oral surgery under local anaesthesia receiving either $4.4 \mathrm{ml}$ lidocaine (lignocaine) with 1:80,000 epinephrine or $4.4 \mathrm{ml} 3 \%$ prilocaine with $0.03 \mathrm{IU} / \mathrm{ml}$ felypressin.

Results Cardiac transplant patients experienced a significant tachycardia 10 minutes after injection of the epinephrine-containing solution. No significant change in heart rate was detected after the injection of an epinephrine-free solution. Blood pressure was not affected. Periodontal surgery did not affect the responses to the local anaesthetics in the transplant recipients.

Conclusions The cardiovascular response to dental local anaesthesia in cardiac transplant recipients is governed by the solution injected.

Survival following cardiac transplantation increased dramatically following the introduction of cyclosporin as an integral component of immunosuppressive therapy.

However, cyclosporin may produce a range of unwanted effects including gingival overgrowth. Thirty percent of dentate cardiac transplant patients experience this unwanted effect with a severity that requires surgical intervention. This figure may rise to more than $60 \%$ in patients additionally medicated with a calcium channel blocking agent. ${ }^{1}$ Gingival surgery is normally performed under local anaesthesia which, to reduce local bleeding is usually delivered with a vasoconstrictor. Solutions which contain epinephrine (adrenaline) are normally preferred. ${ }^{2}$

Studies investigating the haemodynamic effects of epinephrine-containing and epinephrine-free local anaesthetics in healthy

\footnotetext{
${ }_{1 *}$ Senior Lecturer in Oral Surgery, University of Newcastle, ${ }^{2}$ Consultant Physician in Cardiac Transplantation, Department of Cardiology, Freeman Hospital, Newcastle upon Tyne, ${ }^{3}$ Research Student, Dental School, University of Newcastle, ${ }^{4}$ Senior Lecturer, Restorative Dentistry, University of Newcastle

${ }^{*}$ Correspondence to: J. G. Meechan, Oral and Maxillofacial Surgery, Dental School, University of Newcastle upon Tyne, Framlington Place, Newcastle upon Tyne NE2 4BW Email:j.g.meechan@ncl.ac.uk
}

volunteers and patients have shown little effect on cardiovascular function. ${ }^{3-6}$ However transplanted hearts are supersensitive to circulating catecholamines. ${ }^{7,8}$ Therefore, cardiac transplant recipients receiving catecholamines for dental treatment may react differently from healthy patients. The aim of the present study was to examine the effects of administration of a local anaesthetic agent containing epinephrine at a concentration of $1: 80,000$ in patients who had undergone cardiac transplant and compare these findings with a group of cardiac transplant recipients receiving an epinephrine-free local anaesthetic and with otherwise healthy controls requiring an epinephrine-containing local anaesthetic for minor oral surgery.

\section{MATERIALS AND METHODS}

Thirty patients participated in the study following ethical approval. Informed written consent was obtained from each patient. Ten patients were healthy controls and the twenty cardiac transplant recipients were divided into two groups of ten. Cardiac transplant recipients were more than three months post-transplant and medicated with cyclosporin together with other immunosuppressive agents and all received gingival surgery. Non-transplant controls were patients requiring local anaesthesia for a minor oral surgical procedure. Patients medicated with beta-adrenergic blocking drugs were excluded. Patient age was recorded and the time from transplant surgery was noted for the transplant recipients.

The leads from a 12 lead ECG recorder and the cuff of an automatic blood pressure recorder were attached to the patient who was placed supine and allowed to rest for ten minutes. ECG, blood pressure and heart rate recordings were made after the rest period. One minute following pre-injection measurements, $4.4 \mathrm{ml}$ of a local anaesthetic solution was injected over three minutes as maxillary buccal and palatal infiltration anaesthesia. The solution was either 2\% lidocaine (lignocaine) with 1:80,000 epinephrine or 3\% prilocaine with $0.03 \mathrm{IU} / \mathrm{ml}$ felypressin. The ten healthy patients all received lidocaine with epinephrine, one group of ten cardiac transplant recipients received the lidocaine/epinephrine solution and the other ten were given prilocaine with felypressin. The patient was unaware of the identity of the solution. The worker interpreting the ECG recordings was blinded to both solution and patient group. Immediately following injection heart rate, blood pressure and ECG were recorded. These readings were repeated 10 


\begin{tabular}{|c|c|c|c|c|}
\hline Group & $\begin{array}{l}\text { Pre-injection } \\
\text { value }\end{array}$ & $\begin{array}{l}\text { Increase from } \\
\text { pre-injection value at } \\
0 \text { mins post-injection. }\end{array}$ & $\begin{array}{l}\text { Increase from } \\
\text { pre-injection value at } \\
10 \text { minutes post-injection }\end{array}$ & $\begin{array}{l}\text { Increase from } \\
\text { pre-injection value } \\
4 \text { minutes into surgery } \\
\text { (15 minutes post-injection) }\end{array}$ \\
\hline Trans with no epi $n=10$ & $83.9 \pm 12.9$ & $2.3 \pm 6.5$ & $-0.2 \pm 6.8$ & $2.3 \pm 5.5$ \\
\hline Trans with epi $n=10$ & $94.6 \pm 12.5$ & $8.7 \pm 5.8$ & $23.0 \pm 7.1$ & $18.8 \pm 4.9$ \\
\hline Healthy with epi $n=10$ & $74.0 \pm 9.0$ & $5.1 \pm 8.8$ & $4.8 \pm 7.9$ & - \\
\hline
\end{tabular}

\begin{tabular}{|c|c|c|c|c|}
\hline Group & $\begin{array}{l}\text { Pre-injection } \\
\text { value }\end{array}$ & $\begin{array}{l}\text { Increase from } \\
\text { pre-injection value at } \\
0 \text { mins post-injection }\end{array}$ & $\begin{array}{l}\text { Increase from } \\
\text { pre-injection value at } \\
10 \text { minutes post-injection }\end{array}$ & $\begin{array}{l}\text { Increase from } \\
\text { pre-injection value } \\
4 \text { minutes into surgery } \\
\text { (15 minutes post-injection) }\end{array}$ \\
\hline Trans with no epi $n=10$ & $141.1 \pm 9.2$ & $5.6 \pm 8.7$ & $-1.7 \pm 5.0$ & $10.1 \pm 11.4$ \\
\hline Trans with epi $n=10$ & $135.1 \pm 14.3$ & $0.4 \pm 12.3$ & $3.1 \pm 7.8$ & $4.3 \pm 10.7$ \\
\hline Healthy with epi $n=10$ & $138.3 \pm 18.3$ & $-0.7 \pm 5.9$ & $-1.9 \pm 5.7$ & - \\
\hline
\end{tabular}

\begin{tabular}{|c|c|c|c|c|}
\hline Group & $\begin{array}{l}\text { Pre-injection } \\
\text { value }\end{array}$ & $\begin{array}{l}\text { Increase from } \\
\text { pre-injection value } \\
\text { at } 0 \text { mins post-injection }\end{array}$ & $\begin{array}{l}\text { Increase from } \\
\text { pre-injection value } \\
\text { at } 10 \text { minutes post-injection }\end{array}$ & $\begin{array}{l}\text { Increase from } \\
\text { pre-injection value } \\
4 \text { minutes into surgery } \\
\text { (15 minutes post-injection) }\end{array}$ \\
\hline Trans with no epi $n=10$ & $87.0 \pm 8.3$ & $2.3 \pm 5.9$ & $2.4 \pm 6.8$ & $5.3 \pm 6.7$ \\
\hline Trans with epi $n=10$ & $88.7 \pm 12.9$ & $-2.2 \pm 8.3$ & $-0.9 \pm 5.3$ & $-2.9 \pm 5.3$ \\
\hline Healthy with epi $n=10$ & $81.8 \pm 10.2$ & $-1.2 \pm 6.9$ & $0 \pm 4.1$ & - \\
\hline
\end{tabular}

minutes following the end of the injection and surgery began one minute after the ten minute recording. Recordings were repeated in the transplant recipients four minutes into the surgical procedure (15 minutes after injection).

Statistical analyses were performed using ANOVA and Student's paired and unpaired $t$-tests. Significance is expressed at the 5\% level.

\section{RESULTS}

There was no significant difference in the ages of the groups. The mean ages ( \pm standard deviations) for the transplant patients who received prilocaine with felypressin and the epinephrine-containing solutions respectively being $47.3 \pm 13.8$ years and $44.0 \pm 11.4$ years; the healthy patients aged $34.4 \pm 13.3$ years $(\mathrm{F}=2.76)$. The transplant group who received the epinephrine-free solution were $32 \pm 13.7$ months post transplant; those who received the epinephrine-containing solution were $34 \pm 17.4$ months post-transplant $(\mathrm{t}=0.06$, not significant).

The results are shown in Tables 1-3. Immediately after injection there was no significant difference in the changes in heart rate from pre-injection levels between the groups $(\mathrm{F}=2.0 ; \mathrm{p}=$ 0.154). However, cardiac transplant recipients showed a significant rise in heart rate ten minutes following injection of the epinephrine-containing local anaesthetic $(t=10.2 ; p<0.001)$. This differed significantly from the changes observed in the healthy patients and in the transplant group who received prilocaine with felypressin $(F=27.8 ; p<0.001)$. The difference in heart rate between treatments for the transplant recipients was still apparent during surgery $(\mathrm{t}=6.9 ; \mathrm{p}<0.02)$.
There were no significant differences between groups in changes in systolic and diastolic blood pressure from pre-injection measurements immediately after ( $\mathrm{F}=0.29$ and 0.34 respectively) and ten minutes following ( $\mathrm{F}=2.02$ and 0.96 respectively) injection. Similarly, there were no significant changes from base-line blood pressure measurements in the transplant patients with either local anaesthetic four minutes into surgery.

No specific effects on ECG were detected in the healthy patients or in the transplant recipients.

\section{DISCUSSION}

In this investigation the immediate post-injection readings were taken as an assessment of the response to the act of injection. The ten minute post-injection time shows a response to the solution. In the transplant groups a further reading was taken four minutes into the surgical procedure to assess the effect of surgery on their haemodynamic responses.

Previous studies with volunteers and patients awaiting minor oral surgery have shown no significant effects on heart rate and systolic blood pressure immediately after and ten minutes following the injection of epinephrine-containing local anaesthetics at the doses used in this study.,4 Other studies in volunteers and in patients undergoing periodontal surgery where lower doses of epinephrine have been used have shown similar results. ${ }^{6,9}$ The results of the present study confirm these earlier findings. There was no significant change in heart rate in healthy patients attributable to the injection of $4.4 \mathrm{mls}$ 2\% lidocaine with 1:80 000 epinephrine. However, the cardiac transplant patients showed a significant rise in heart rate following this injection. Such an effect was not 
detected in the transplant recipients after administration of an epinephrine-free solution of identical volume. This finding is in agreement with studies investigating the intravenous administration of epinephrine in cardiac transplant patients which have demonstrated exaggerated increases in heart rate in these patients. ${ }^{10}$ The normal heart is under neurogenic control as well as being influenced by circulating agents such as catecholamines. The transplanted heart, at least in the early post-transplant period, has lost neurogenic control. The most likely explanation for the rise in heart rate in the transplant group following epinephrinecontaining local anaesthesia is supersensitivity to the effects of circulating catecholamines. ${ }^{7,8}$ It is well known that epinephrine enters the circulation rapidly following intra-oral injection. ${ }^{11}$

An earlier investigation into the haemodynamic responses of cardiac transplant recipients to dental treatment ${ }^{12}$ suggested there were no significant haemodynamic changes due to local anaesthesia. Why do the results of that and the present study differ? There are a number of possibilities. Firstly, in the earlier investigation no data are given in relation to the dose of local anaesthetics employed. It may be that less solution was used in that study, certainly a solution containing a lesser concentration $(1: 100,000)$ of epinephrine was injected. Another difference is in the timings of the recordings. In the earlier study readings were taken 5 minutes after the injection and at an indeterminate time after treatment. Previous investigations have shown that biochemical changes peak about ten minutes after injection. ${ }^{3}$

Some studies have suggested that surgical stress can exaggerate haemodynamic influences of the local anaesthetics. ${ }^{13}$ Other investigations have reported that the use of an epinephrine-containing solution negates any lessening of the sympathoadrenal response achieved by sedation. ${ }^{14}$ In the present study the recordings made four minutes into surgery show that the surgical procedure did not influence the haemodynamic effects produced by the local anaesthetics in cardiac transplant recipients. Thus the cardiovascular response of heart transplant recipients to periodontal surgery under local anaesthesia seems to be influenced more by the anaesthetic than the surgery.

The present study does not ideally isolate the effect of epinephrine, as the solutions used in the transplant groups contained different anaesthetics agents. Ideally the epinephrine-free solution to use as a control is plain lidocaine. However, this anaesthetic is less reliable than lidocaine with epinephrine for the production of intra-oral soft tissue anaesthesia. ${ }^{15}$ In addition, good haemorrhage control is required during periodontal surgery and thus the use of a vasoconstrictor-containing solution is preferred. Therefore, in order to ensure reliable pain and haemorrhage control during surgery in this investigation, the prilocaine/felypressin combination was used as the epinephrine-free solution. In addition, previous studies have shown that the cardiovascular responses to intra-oral injections of plain lidocaine and prilocaine and felypressin are similar. ${ }^{3,4}$ Importantly this study compared two vasoconstrictorcontaining solutions which are routinely used in the United Kingdom, thus mimicking accepted clinical practice.

Advice exists concerning reduction of the dose of epinephrine in dental local anaesthetics for patients with cardiac disease. ${ }^{16}$ There are no recommendations relating to cardiac transplant recipients. The results of this investigation suggest that epinephrine dose-response studies are merited so that sensible recommendations can be made for the treatment of cardiac transplant recipients under local anaesthesia in dentistry. Until such evidence is available it may be wise to limit the amount of epinephrine-containing local anaesthetics to a maximum of $4.4 \mathrm{~mL}$ of a $1: 18,000$ solution or to use epinephrine-free solutions such as prilocaine with felypressin as the first choice for dental treatment under local anaesthesia in this group of patients.

1. Thomason J M, Seymour R A, Ellis J S, Kelly P J, Parry G, Dark J. latrogenic gingival overgrowth in cardiac transplantation. J Periodontol 1995; 66: 742-746.

2. Newcomb G M, Waite I M. The effectiveness of two local analgesic preparations in reducing haemorrhage during periodontal surgery. J Dent 1972; 1:37-42.

3. Meechan J G, Rawlins M D. The effect of adrenaline in lignocaine anaesthetic solutions on plasma potassium levels in healthy volunteers. Eur J Clin Pharm 1987; 32: $81-83$.

4. Meechan J G, Rawlins M D. A comparison of the effect of two different local anaesthetic solutions on plasma potassium concentration. Br Dent J 1987; 163: 191-193.

5. Meechan J G, Rawlins M D. The effects of two different dental local anesthetic solutions on plasma potassium levels during third molar surgery. Oral Surg Oral Med Oral Path 1988; 66: 650-653.

6. Chernow B, Balestrieri F, Ferguson C D, Terezhalmy G T, Fletcher R, Lake R. Local dental anaesthesia with epinephrine. Minimal effects on the sympathetic nervous system or on hemodynamic variables. Arch Intern Med 1983, 143: 2141-2143.

7. Carleton R A, Heller S J, Najafi H, Clark J G. Hemodynamic performance of a transplanted human heart. Circulation 1969; 40: 447-452.

8. Gilbert E M, Eiswirht C C, Mealey P C, Larrabee B S, Herrick C M, Bristow M R. badrenergic supersensitivity of the transplanted human heart is presynaptic in origin. Circulation 1989; 79: 344-349.

9. Frabetti L, Checchi L, Finelli K. Cardiovascular effects of local anaesthesia with epinephrine in periodontal treatment. Quintessence Int 1992: 23: 19-24.

10. Roca J, Cruz Caturla M, Hjemdahl P, Masotti M, Ventura A, Oriol A. Effects of adrenaline on ventricular function and coronary haemodynamics in relation to catecholamine handling in transplanted human hearts. Eur Heart J 1993; 14: 474-483.

11. Tolas A G, Pflug A E, Halter J. Arterial plasma epinephrine concentration and responses after dental injection of local anesthetic with epinephrine. J Am Dent Assoc 1982; 104: 41-43.

12. Borca G, Montebugnoli P, Capuzzi P, Vaccaro M A. Circulatory dynamics during dental operations in patients with heart transplants. Quintessence Int 1993; 24: 749-751.

13. Meyer F-U. Haemodynamic changes under emotional stress following a minor ora surgical procedure under local anaesthesia. Int J Oral Maxillofac Surg 1987; 16: 688-694.

14. Dionne R A, Goldstein DS, Wirdzek P. Effects of diazepam premedication and epinephrine-containing local anesthetic on cardiovascular and plasma catecholamine responses to oral surgery. Anesth Analg 1984; 63: 640-646.

15. Meechan J G, Day P F, McMillan A S. Local anaesthesia in the palate: a comparison of techniques and solutions. Anesth Prog 2000; 47: 139-142.

16. Perusse R, Goulet J-P, Turcotte J-Y. Contra-indications to the use of vasoconstrictors in dentistry. Part I. Oral Surg 1992; 74: 679-686. 